Harrison, G., Owens, D., Holton, A., Neilson, D. \& Boot, D. (1988) A prospective study of severe mental disorder in Afro-Caribbean patients. Psychological Medicine, 18, 643-657.

Ineichen, B., Harrison, G. \& Morgan, H. G. (1984) Psychiatric hospital admissions in Bristol. I. Geographic and ethnic factors. British Journal of Psychiatry, 145, 600-604.
PERKINS, R. E. \& Rowlands, L. (1986) Planning community services for people with major long-term needs: The Maudsley experience. Paper presented at National MIND/Maudsley Joint Conference, Institute of Psychiatry, London.

Rogers, A. \& Faulkner, A. (1987) A Place of Safety: MIND's Research into Police Referrals to the Psychiatric Services, London: MIND Publications.

\title{
The white coat and the liaison psychiatrist
}

\author{
Alan N. Wear, Squibb Research Fellow, Oxford Project to Investigate Memory and \\ Ageing, Radcliffe Infirmary, Oxford OX2 6HE
}

Medical care in general hospitals is a collective activity and liaison psychiatrists may become part of this process. Cornerstones of successful management are co-operation with colleagues and 'teamwork', although these elusive goals are not always achieved. A shared uniform is one possible solution to improve this teamwork, the white coat being the livery of the hospital doctor. Furthermore, patients may appreciate a uniform. One survey of 200 North American general hospital in-patients showed the white coat to be surprisingly popular (Dunn et al, 1987); $65 \%$ of those replying wanted to see their doctor in a white coat. But the white coat is often unpopular with doctors and perhaps a more relevant question is whether it makes any difference to patient behaviour.

In psychiatric wards this has been studied in relation to nursing uniform. One study (Klein et al, 1972) could detect no difference in patient behaviour under a variety of dress conditions, but another study did find an effect (Rinn, 1976). In a series of six week periods, when the staff wore street clothes, there was a reduction in aggressive behaviour, medication refusals and self-punitive responses as compared to similar periods of study with staff wearing either uniform or a mixture of uniform and street clothes. It was concluded that street clothes create a therapeutic milieu. No parallel studies have been undertaken in general hospitals, so the psychiatrist can choose.
Does he join the company and wear the uniform or are there other ways of working with general hospital patients and colleagues?

To find out what happens in practice, a small survey was undertaken. A short questionnaire was sent to consultants in adult mental illness in the Oxford region and to selected senior registrars working with the Liaison Service in Oxford $(n=66)$. A short letter of explanation was included.

\section{Findings}

Of 66 questionnaires sent, 50 were returned giving a response rate of $75 \%$. The questions and responses are set out below:

Do you ever wear a white coat in the course of your clinical practice?

Eighty-eight per cent of respondents never wore a white coat at any time. The frequency with which this group worked in the general hospital varied from daily to less than one visit per month, with a modal value of weekly. Comparison with the $12 \%$ of respondents who did use a white coat is difficult because of the sevenfold difference in size of the two groups. However, among white coat wearers, the modal frequency for general hospital work was daily with a range from daily to less than once per month. This 
marginal increase in general hospital work among the wearers suggests that there are advantages to wearing a white coat that only become apparent with continuous liaison work.

Do you think there are particular types of setting where a white coat is beneficial?

Thirty-two per cent recognised the benefit of a white coat and suggested situations where it was useful. Examples included interviewing patients with organic confusional states or particular clinical settings such as an infectious diseases unit where protection was important.

Do you think there are particular types of setting where the white coat is detrimental?

Seventy-two per cent agreed there was a damaging side to the white coat. Interviewing anxious or young patients and treating paranoid illnesses were mentioned by respondents as examples where white coats might best be left off.

Do you think the white coat is more than a protection of one's own clothing

This loaded question was attempting to ascertain whether the white coat held a symbolic value; $88 \%$ of respondents agreed there was an additional value attached to the white coat. Interestingly of the remaining $12 \%$, none used a white coat, suggesting that those who did use a white coat were sensitive to the white coat's other functions.

\section{Comment}

The uniform unpopularity of the white coat is probably a result of several influences. First, it is often inconvenient to wear, secondly psychiatric ward culture discourages uniform and the white coat has a history and cultural context which may have made it unpopular.

The history of the white coat is closely connected with the emergence of scientific medicine. In the 1880 s surgeons started to use protective gowns to reduce the risk of infecting patients. With the growth of laboratory medicine so the 'lab' coat moved to the bedside and protected the doctor and displayed the new power of modern medicine (Blumhagan, 1979). The whiteness probably came later as medical success gave doctors a new credibility that distinguished them from some of the questionable practices of the 18 th century.

This new whiteness has interesting connections. First, white, the opposite of black, represents a symbol of life-a power over death. Whiteness as so many washing powder adverts tells us also symbolises purity. A purity of intention, that is truthfulness (Latin, Candidus = white) and also an internal purity, for example the innocence exemplified by bridal gowns. The combination of purity and power over death are qualities found only among the angelic $-\mathbf{a}$ tall order indeed.

If symbols do influence behaviour then it is clearly not an image to be taken lightly. For psychiatrists assessment of "unpopular patients" (Stockwell, 1972) will not be helped by wearing a white coat.

The relationship between psychiatrist and medical colleague is not always easy and while white coats may smooth the inter-disciplinary alliance their infrequent use suggests that other methods are available; in other words team membership need not be based on uniform.

\section{Acknowledgements}

I am grateful to all the respondents who replied to the questionnaire. I would also like to thank Drs E. B. O. Smith and R. Mayou for their advice and encouragement.

\section{References}

Blumhagan, D. W. (1979) The doctor's white coat. Annals of Internal Medicine, 91, 111-116.

Dunn, J. J., Lee, T. H., Perclay, J. M., Fitz, J. G. \& Goldman, L. (1987) Patient and house officer: attitudes on physician attire and etiquette. Journal of American Medical Association, 257, 65-68.

Klein, R. H., Pillsbury, J., Bushey, M. \& SNell, S. (1972) Psychiatric staff: uniform or street clothes? Archives of General Psychiatry, 26, 19-22.

RINN, R. C. (1976) Effects of nursing apparel upon psychiatric behaviour. Perceptual and Motor Skills, 43, 936-945.

Stockwell, F. (1972) The Unpopular Patient. London: Royal College of Nursing. Pp. 67-68. 